www.periodicos.unimontes.br/index.php/caminhosdahistoria

\title{
POLÍTICA E PODER EM “OS SIMPSONS NO BRASIL"
}

\begin{abstract}
Alessandro de Almeida ${ }^{1}$
Resumo: O ex-presidente Fernando Henrique Cardoso e a empresa de turismo Rio Tur se incomodaram com o episódio dOs Simpsons, intitulado "O feitiço de Lisa". Diante desse trauma, o impacto do desenho na política brasileira ficou evidente. A partir desse indício justificamos nossa análise e o recorte temporal, pois o então presidente da República brasileira chegou a exigir desculpas públicas do autor do desenho animado Matt Groening, além do fato de que a Rede Globo de televisão e a empresa de Turismo do Rio de Janeiro terem se posicionado publicamente contra a representação de Brasil expressa ironicamente no episódio "O feitiço de Lisa". Neste a família Simpson viaja para o Brasil que é um país representado por valores fúteis, marcado por sequestros, sexualidade, pobreza, futebol, carnaval, favelas, corrupção, falta de crenças, dentre outras características pejorativas. Com o intuito de perceber a relação existente entre o poder midiático (televisão) na política, utilizaremos além do próprio episódio a análise de outras fontes como jornais, revistas, páginas de internet do autor ou mesmo de fãs que comentam o capítulo do desenho em evidencia. Dessa maneira, nos preocuparemos também com as percepções dos telespectadores acerca do episódio com vistas a nos aproximarmos das motivações que fizerem deste um desenho polêmico.
\end{abstract}

Palavras-chave: Poder; televisão; política; desenho; Brasil.

Abstract: Former President Fernando Henrique Cardoso and the tourism company Rio Tur were annoyed by the episode of The Simpsons, entitled "Blame it on Lisa". In the face of this trauma, the impact of this animation movie on Brazilian politics was evident. Based on this, we justify our analysis and the time frame, since the then President of the Brazilian Republic, Fernando Henrique Cardoso, demanded public apologies from the author of the animation movie, Matt Groening. In addition, TV Globo network and the Rio de Janeiro tourism company have publicly positioned themselves against the representation of Brazil expressed ironically in the episode "Blame it on Lisa". In this, the Simpson family travels to Brazil which is a country represented by futile values, marked by kidnappings, sexuality, poverty, soccer, carnival, slums, corruption, lack of beliefs, among other pejorative characteristics. In order to understand the relationship in the power of media (television) in politics, we will use in addition to the episode itself the analysis of other sources such as newspapers, magazines, internet pages of the author or even fans who comment on the episode researched. In this way, we will also be concerned with the viewers' perceptions of the episode in order to approach the motivations that make this a controversial animation movie.

Keywords: Power; television; politics; animation movie; Brazil.

\footnotetext{
${ }^{1}$ Alessandro de Almeida. Doutor em História Social. Professor de História Moderna e Contemporânea do Departamento de História da Universidade Estadual de Montes Claros - UNIMONTES. E-mail: hg6alessandro@gmail.com ou @hg6alessandro.https://orcid.org/0000-0003-3348-4489.
} 
Criado em 1987, o desenho "Os Simpsons" se notabilizou por colocar em relevo questões importantes sobre a política americana e internacional. Considerado pelo público comum como uma animação que "prevê o futuro", a produção audiovisual americana, em sua organização e composição, problematiza questões importantes da sociedade. Para esse fim, o desenho conta com uma dezena de intelectuais na produção de cada episódio de duração de aproximadamente dez minutos. Dessa forma, questões relevantes sobre a cultura política são levantadas e, dado o sucesso e longevidade da série, a repercussão é difundida e pode incomodar lideres políticos e empresários.

No ano de 1991, a série Os Simpsons foi apresentada no Brasil pela primeira vez. Logo caiu nas graças do público que, cada vez mais, se divertia com a família americana de classe média retratada no desenho animado ${ }^{2}$. Além, desse constante contato que o público brasileiro passou a ter com a série animada, os animadores e produtores do desenho, em alguns episódios, retrataram diretamente o Brasil. Tais imagens simpsonizadas provocaram atitudes diversas que ilustram o diálogo e as apropriações que o público brasileiro faz do desenho. Sob tal prisma, é que direcionamos o olhar, procurando perceber as dimensões políticas e sociais desse entretenimento lucrativo, que se relaciona com inúmeros brasileiros há mais de duas décadas.

Enunciados do tipo: "Marge, lembre-se, se algo der errado na usina, culpe o cara que não sabe falar inglês!”’3, pronunciadas no desenho pelo personagem ficcional Homer Simpson, têm provocado repercussões no público, uma vez que sugere discriminação, ou, até mesmo aversão a estrangeiros. Provocações desse tipo, quando direcionadas ao Brasil, apresentadas na televisão ou Internet suscitaram os incômodos iniciais que nortearam nossas investigações, pois percebemos, gradativamente, que os significados, ou ressignificações poderiam ir para além de meras inferências depreciativas a respeito nosso país e de seus cidadãos. Por isso mesmo, as repercussões das frases de Homer Simpson, ou as peripécias vividas por outros personagens da família, ultrapassam com frequência o ambiente da cidade fictícia de Springfield, colocando autoridades, celebridades artísticas, membros da comunidade científica e detentores de diversas ordens e hierarquias em situações problemáticas. Sob essa ótica, o

\footnotetext{
${ }^{2}$ Estima-se que Os Simpsons seja visto semanalmente por aproximadamente 40 milhões de pessoas. E, anualmente, por 10 bilhões de pessoas em todo o mundo. A reapresentação dos Simpsons na TV Globinho, em 2008, fez com que a audiência chegasse a 10 pontos percentuais de média ocupando a liderança do ranking do Ibope. Entretanto, na $20^{\mathrm{a}}$ Temporada (2010), o desenho vem perdendo audiência nos Estados Unidos para os concorrentes indiretos American Dad e Uma Família da Pesada. Ver em: http://pt.simpsons.wikia.com/wiki/User_blog:Aero\%27Guns/O_que_voc\%C3\%AA_far\%C3\%A1_quando_Os_S impsons_n\%C3\%A3o_ser_mais_exibido\%3F. Acesso em: maio 2011.

${ }^{3}$ Ao clicar em The Simpsons no site: http://meadd.com/osimpsons. Você irá ler a frase de Homer de critica a estrangeiros. Acesso em: mar. 2003.
} 
poderio do desenho entra em relevo e o caráter politicamente incorreto da série marcado por suas provocações satíricas, deixou marcas no Brasil, com o episódio "O feitiço de Lisa" proibido no país, para a transmissão nos canais de televisão aberto de rede nacional.

No que a televisão na contemporaneidade, sabe-se que é o meio de comunicação de massa mais utilizado pela população brasileira. $\mathrm{O}$ desenvolvimento acelerado da tecnologia foi acompanhado de uma ampliação do potencial de velocidade com que as informações são proferidas, atingindo públicos diversos. Em meio a esta situação o processo de globalização e o intuito de intercambiar culturas mundiais, contribuíram também para facilitar o acesso dos indivíduos a meios de comunicação como rádio, cinema, Internet e principalmente a televisão, mesmo em países de menor desenvolvimento econômico. Nesse sentido, denuncias de corrupção, planos de governo, vida particular de políticos, propostas partidárias e diversas situações decorrentes do cenário político passaram a estar diante dos "olhos" dos brasileiros. Mesmo em telenovelas ou propagandas de empresas particulares os embates políticos passaram a ser insistentemente intermediado pela televisão, fato que justifica os estudos sobre cultura política poderem ser pautados ou discutidos a partir da análise de fontes audiovisuais. "Diante da televisão não existe somente telespectadores. Por que cada vez são mais complexas as interações entre mídia e cidadania, entre televisão e política." (MARTINBARBERO, 2004, p. 93).

Sobre a condição humana, Hanna Arendt afirma que os cidadãos pertenciam a duas ordens de existência, fundamentadas no que é seu (idion) e no que é comunal (koinon). Assim ela acreditava que ser político nas cidades Estado gregas significava tudo que se dizia por palavras e por persuasão em detrimento da violência. Nesse sentido ela já indicava a inseparável união entre retórica, comunicação e política. Nesse viés ela afirma ainda que o público é "o que pode ser visto por todos" ou que tenha maior visibilidade possível, assim ela ressalta ainda mais a importância da comunicação para os embates políticos gregos. Pensando na atualidade da perspectiva arendtiana percebemos que os meios de comunicação de massa, sobretudo a televisão, passam a ser de vital importância para compreendermos os embates políticos que circundam o cotidiano político do Brasil. Mesmo estudando enfocando a democracia grega, ao considerarmos a retórica como base para o ser político e o público como aquilo que pode ser visto por todos, sabemos que é a televisão pública ou privada o meio de comunicação que nas últimas décadas passou a ser a base dos discursos e das propagandas persuasivas dos políticos exatamente pelo fato de potencializar a maior visibilidade possível. Contudo, televisão, ser político, público e disputas democráticas passaram a compor a política contemporânea ocidental e nacional. 
Em "A obra de arte na era de sua reprodutibilidade técnica" - publicado em 1935 - o filósofo alemão Walter Benjamin destaca que o cinema seria o agente mais eficaz para destruir a aura ${ }^{4}$ e atingir as massas, ganhando assim uma importância política jamais vista em outro meio de comunicação. Assim o cinema teria a capacidade de quebra a unicidade da obra de arte, pois o poder de reprodutibilidade cinematográfico é muito grande, além de sua capacidade de atingir espaços mutuamente. A possibilidade de exibir a obra de arte em numerosas situações reduz no cinema o culto tradicional existente nas demais obras de arte. Esta modificação na obra de arte segundo Benjamin alterava as percepções e a montagem propiciada pela arte do cinema poderia ser utilizada, por exemplo, por regimes totalitários como o nazista. Nesse contexto o autor acredita que o cinema e sua capacidade de agir sobre os espectadores podem ser utilizados para fins políticos. A perspectiva colocada por Benjamin é fundamental para pensarmos a importância atual da televisão para a política na medida em que esta também aciona as percepções dos telespectadores e pode e é utilizada muitas vezes para a vitória de um candidato em eleições, disputa por mercado entre empresas e mesmo alterações em telenovelas que são condicionadas a opinião pública.

Jesus Martin-Barbeiro em "A comunicação como um novo projeto para a cultura política", destaca que três pontos são fundamentais para se repensar a relação entre meios de comunicação de massa, política e cultura na América Latina, estes são: as experiências com regimes autoritários que fundamentaram reações como a de movimentos artísticos, grupos religiosos e organizações fundamentadas nos direitos humanos que desafiaram a força governamental autoritária imposta; uma segunda questão diz respeito a percepção de que os movimentos e convivências sociais podem modificar os imaginários e os sistemas de construções simbólicas e por último o fato de que o advento do desenvolvimento dos meios de comunicação e da dinâmica da escolarização se colocam na atualidade no centro do cenário político e social. Nesse contexto o autor afirma que:

Abre-se, assim, o debate para um horizonte de problemas novos, em que o
redefinido é tanto o sentido da cultura quanto o da política, onde a
problemática da comunicação entra não somente a titulo temático e
quantitativo - os enormes interesses econômicos que movem as empresas de
comunicação - como também qualitativo: na redefinição da cultura a chave e
a sua compreensão da natureza comunicativa, isto é, seu caráter de processo
produtor de significações e não de mera circulação de informações e
portanto, no qual o receptor não é o mero decodificador que omissor
colocou na mensagem, mas também um produtor. (MARTIN-BARBERO,
1989, p. 86)

${ }^{4}$ Segundo Benjamin aura seria definida como a "aparição única de uma realidade longínqua, por mais próxima que ela esteja." 
Um exemplo interessante da importância da televisão para o acirramento de embates e disputas políticas no Brasil esteve presente em uma reportagem da Revista Veja, em 17 de abril de 2002, onde foi destacada a indignação de representantes políticos e de empresas de turismo da cidade do Rio de Janeiro frente ao polêmico episódio de um desenho em que a família Simpsons vem para o Brasil. Após uma construção imagética extremamente depreciativa do Brasil, a mesma revista declara:

O humor politicamente incorreto do desenho animado americano Os Simpsons desembarcou no Brasil e fez estrago. Em um episódio que acaba de ser exibido nos Estados Unidos, a família decide visitar o Rio de Janeiro e se mete em uma série de confusões. Aparecem ruas cheias de ratos e trombadinhas. Um táxi clandestino sequestra o patriarca, Homer. Macacos e sucuris andam pela cidade. O pestinha Bart se dedica a aprender espanhol antes da viagem e a trilha sonora é de ritmos caribenhos. A Riotur, empresa de turismo do Rio, anunciou que vai processar a Fox, produtora do desenho animado. O episódio deve ser exibido no Brasil apenas em outubro. Outros países já foram alvo desse tipo de gozação, sem maiores consequências. (VEJA, 2002)

A ridicularização do Brasil incomodou "a Riotur, empresa de turismo do Rio", o presidente Fernando Henrique Cardoso (1994-2002) e a própria Rede Globo de televisão, proibiram a veiculação do episódio em sua programação, sendo este restrito apenas a canais de televisão por assinatura como a FOX. Demonstrando a inquietude diante da exibição do episódio, o líder do executivo brasileiro exigiu desculpas dos produtores do programa. No dia 13 de abril de 2002, o jornal Folha de São Paulo, destacou que:

A produção do desenho animado "Os Simpsons" pediu desculpas ontem pelo
episódio "Blame it on Lisa", que escarnecia do Rio, mas aproveitou para
provocar o presidente Fernando Henrique Cardoso. "Pedimos desculpas à
amável cidade do Rio de Janeiro", disse o produtor James L. Brooks. "Se
isso não resolver a questão, Homer Simpson se oferece para lutar com o
presidente do Brasil no 'Celebrity Boxing'."
Ele se referia ao novo programa da Fox, emissora de "Os Simpsons", que
reúne duas celebridades já em decadência para uma luta de boxe. (FOLHA
DE SÃO PAULO, 2002)

Pode-se depreender que, do comentário acima, emerge uma associação da figura do presidente Fernando Henrique Cardoso às "celebridades já em decadência", fato interessante para pensarmos a importância política do episódio "O Feitiço de Lisa". Em 2002, os brasileiros viviam, um momento de grave crise social decorrente, entre outros fatores, da crise do Plano Real, do "efeito dominó" da globalização que assolou os países do mundo, após sucessivas crises econômicas na Rússia e nos tigres asiáticos, no final da última década do século XX. Nesse sentido, a confiança dos brasileiros no governo federal estava gravemente abalada e a imagem do presidente brasileiro estava, de certa forma, em decadência. No 
episódio "O feitiço de Lisa" várias passagens pode ser associado às práticas políticas presentes no governo Fernando Henrique Cardoso. Em um primeiro momento é percebido pela família Simpson que as contas de telefone estão chegando com um valor muito auto, como é comum na série o primeiro culpado foi Bart Simpson, mas a personagem Lisa Simpson é que era a culpada. De forma natural a personagem afirmou que os excessivos telefones foram realizados com o intuito de ajudar um órfão brasileiro chamado de "Ronaldinho". Desse início do desenho evidencia-se obviamente a dependência econômica decorrente, sobretudo das vinculações do governo brasileiro com o Fundo Monetário Internacional, vínculos estes reforçados pelo presidente Fernando Henrique em seus dois mandatos (1994-2002). Outro aspecto interessante é que ao viajarem para o Brasil a família Simpson (procurando o Ronaldinho para ajudá-lo) se depara com inúmeros problemas sociais que devido a sátira do desenho podem causar um impacto que incomoda o telespectador. Nesse contexto, Homer (o pai da família) foi sequestrado no Rio de Janeiro, os demais membros da família foram assaltados por crianças e assediados sexualmente nas ruas e as maneiras pelas quais o brasileiro conseguia se divertir mediante problemas desse tipo era por meio do futebol e do carnaval. Na perspectiva de ressaltar problemas sociais e dependência econômica no episódio, Homer ao chegar ao Brasil tenta chutar sua mala e deixa cair um livro que diz "Como pilhar o Brasil", ainda nesse viés ao visitar Copacabana sua camisa tinha o desenho do "Tio Sam" engolindo o mundo. Ou seja, a autor Matt Groening ressaltou no episódio em análise problemáticas concernentes aos pontos de maior fragilidade da realidade social brasileira, destacados pela própria mídia nacional, no governo de Fernando Henrique, cuja popularidade em 2002 era no mínimo questionável. Atentando-nos para esta questão, enfatizamos conforme Poul A. Cantor que a política presente no desenho dOs Simpsons é pautada desde seu primeiro episódio "na falta de confiança no poder e, principalmente, no poder distante das pessoas comuns". (CANTOR, 2004: 166).

Luis Felipe Miguel ao estudar acerca das relações existentes entre política e mídia no Brasil ressalta algumas questões interessantes para pensarmos a importância dos meios de comunicação de massa para a política nacional, sobretudo quando ressalta os vínculos existentes entre as eleições de Fernando Henrique Cardozo nas eleições de 1994 e 1998. Acerca da relação existente entre mídia e política no Brasil ele destaca alguns episódios interessantes: em um primeiro momento ele enfatiza a importância de Assis Chateaubriand para a criação da Aliança Liberal que fomentou a revolução de 1930. Nesta O Diário dos 
Associados ${ }^{5}$ primeira rede de comunicação de massa a nível nacional contribui muito para transformar um evento de esfera privada como a morte de João Pessoa (candidato à vicepresidente de Vargas na derrota nas eleições de 1930) em um episódio dramático que legitimou a subida ao poder de Getúlio Vargas na Revolução de 30. Além disto, ele destaca que com o advento da televisão os empresários destas industrias culturais mantinham vínculos políticos claros, como é o caso de Antônio Carlos Magalhães que era o dono da filial da Rede Globo na Bahia e foi ministro das Comunicações no governo do primeiro presidente da republica após a ditadura militar, presidente José Sarney. "Só durante o governo Sarney (1985-1990), pelo menos 91deputados e senadores ganharam concessões para emissoras de rádio e TV.” (MIGUEL, 2002, p. 32). Ainda acerca da mídia e história nacional o autor aponta a hegemonia comunicativa da Rede Globo de Televisão e seu claro apoio e crescimento na ditadura militar, sobretudo a partir da inauguração do Jornal Nacional e do investimento no entretenimento, principalmente materializado nas telenovelas. No período de abertura política do Brasil, o número de aparelhos televisivos no Brasil crescia em uma velocidade espantosa e apesar da frustração da Rede Globo em 1982 quando tentou impedir a eleição de Leonel Brizola para governador do Rio de Janeiro, o papel dessa emissora foi decisivo para as eleições de Collor em 1989 e as de Fernando Henrique Cardozo em 1994 e 1998. Dessa maneira ele destaca que:

$\mathrm{Na}$ primeira disputa, houve o favorecimento 'às claras' do candidato Fernando Collor de Mello, seja pelo viés do noticiário, seja por representação alegórica (mas imediatamente apreensível) na programação de entretenimento. Em 1994, contudo, a adesão é menos personalizada - a tal ponto que o candidato nem precisa aparecer, um ministro pode ser posto em seu lugar. $\mathrm{O}$ favorecimento a Fernando Henrique Cardoso se faz mediante ao plano econômico da mesma bandeira que norteava sua campanha, a fé no Brasil. Em 1998, por fim, a intervenção toma a forma de uma aparente omissão. A campanha eleitoral se torna invisível, evitando o debate sobre políticas alternativas à de Fernando Henrique. Bem mais sutil, essa estratégia busca parecer a 'imparcialidade absoluta'. (MIGUEL, 2002, p. 54)

Atendo-nos à relação de Fernando Henrique Cardoso com a mídia, principalmente a Rede Globo de Televisão ressalta-se que no dia $1^{\circ}$. de setembro o ministro da Fazenda que havia substituído FHC, Rubens Ricúpero, em uma entrevista distraída com um repórter “declarou sua posição de 'propagandista da nova moeda' era uma forma de promover o candidato oficial". Por uma falha técnica, a conversa pôde ser captada por antenas parabólicas residenciais e alguns telespectadores gravaram-na. Ele admitiu manipular dados econômicos

\footnotetext{
5 Rede de jornais e mais tarde redes de rádio e televisão construída pelo empresário Assis Chateaubriand que marcou as relações existentes entre mídia e cultura política no Brasil.
} 
para favorecer Fernando Henrique Cardoso e afirmou que faria tudo para elegê-lo com o intuito de se manter no ministério. Destacou ainda que sua posição era conveniente para a Rede Globo, pois esta emissora dava-lhe espaço para fazer propaganda do plano real fato que favorecia Fernando Henrique Cardoso e impedia os demais candidatos de contra-atacar (MIGUEL, 2002). Acerca das eleições de 1998 destacamos que:

O esvaziamento da cobertura eleitoral pela Rede Globo, em seu telejornal mais assistido, era perfeitamente congruente com a estratégia traçada por Fernando Henrique para sua reeleição. O governo buscou desinflar o processo sucessório, transformando-o em um simples ritual do presidente ao cargo. Para um governante que já exercia a presidência e se mantinha com índices razoáveis de aprovação popular, não era interessante ampliar a discussão sobre as alternativas a sua gestão ou sobre prioridades políticas divergentes. (MIGUEL, 2002, p. 47).

Diante dessa importante vinculação existente entre Fernando Henrique Cardoso e a Rede Globo de Televisão, expressa acima, torna-se mais uma vez interessante pensarmos sobre a limitação de público (ou escolha) que fundamentou a proibição do episódio "O feitiço de Lisa”. No dia 23 de novembro de 2005, Willian Bonner, jornalista e editor-chefe do Jornal Nacional recebeu a visita de professores universitários que ouviram Bonner fazer algumas considerações sobre o jornal e seu trabalho. Ao comentar sobre o público telespectador do Jornal Nacional o jornalista comparou os telespectadores ao personagem Lineu (do programa a Grande Família) e a Homer Simpson fato que lhe gerou sérios transtornos, pois o professor universitário Laurindo Lalo Leal teceu fortes criticas a Bonner. Tentando se explicar em dezembro de 2005, Willian Bonner afirmou que:

Nestas ocasiões, sempre abordo, por exemplo, a necessidade de sermos rigorosamente claros no que escrevemos para o público. Brasileiros de todos os níveis sociais, dos mais diferentes graus de escolaridade. E o didatismo que buscamos para o público de menor escolaridade não deve aborrecer os que estudaram mais. Neste desafio, como exemplo do que seria o público médio nessa gama imensa, às vezes cito o personagem Lineu, de A Grande Família. Às vezes, Homer, de Os Simpsons. Nos dois casos, refiro-me a pais de família, trabalhadores, protetores, conservadores, sem curso superior, que assistem à TV depois da jornada de trabalho. No fim do dia, cansados, querem se informar sobre os fatos mais relevantes do dia de maneira clara e objetiva. Este é o Homer de que falo.

Ao afirmar que o Jornal Nacional procura atingir um público "cansado" de "pais trabalhadores, protetores, conservadores, sem curso superior", Bonner destaca um perfil de brasileiro ao qual o referido jornal, mantendo o seu mesmo formato, desde a Ditadura Militar informa cerca de 50 milhões de brasileiros. Dessa maneira, o própria presidente Emilio Médici, chegou a afirmar: 
Sinto-me feliz todas as noites, quando ligo a televisão para assistir o jornal. Em outros países greves, atentados, conflitos. No Brasil não. O Brasil marcha em paz rumo ao desenvolvimento. É como se tomasse um tranquilizante após um dia de trabalho. (BETTI, 1999, p. 2003).

Segundo Luis Felipe Miguel, o Jornal Nacional além de contribuir para a ascensão de lideranças políticas no Brasil, manteve sua formatação, iniciada em $1^{\circ}$. de setembro de 1969. Em relação ao público alvo ele destaca que existe "uma antiga prática da emissora, de oferecer informações diferenciadas para o público 'qualificado' dos telejornais menos assistidos. Os trabalhadores comuns que ligam a TV após o jantar devem se contentar com o Jornal Nacional.” (MIGUEL, 2002, p. 47).

Percebamos como a ideia de um trabalhador cansado como público é explicita tanto nas justificativas de Willian Bonner, no depoimento do ex-presidente Médici, ou mesmo no comentário do doutor em Ciências Sociais Luis Felipe Miguel. O desenho dOs Simpsons apresentado pela Rede Globo por volta das 11:30h atinge um grande público, sobretudo devido a sua veiculação ser feita exclusivamente aos sábados. Um episódio problemático como "O feitiço de Lisa" poderia gerar uma inquietação no telespectador que em nada condiz com o número grande de informações e a superficialidade de noticiais que foi alvo das criticas do professor Laurindo Lalo Leal que responde a Bonner afirmando que:

A questão central não é o perfil do Homer Simpson (embora o personagem tenha sido usado várias vezes pelo editor-chefe do JN como forma de caracterizar - pejorativamente - o telespectador médio brasileiro) e sim a forma como são escolhidas as matérias que vão ao ar no telejornal de maior audiência do país.

Fui editor de diferentes telejornais e por onde passei nunca vi uma seleção de matérias feita de forma tão rasteira e superficial, tendo como referência apenas as opiniões e idiossincrasias do editor-chefe, como a que presenciei no Jornal Nacional. (Disponível em http://www.bluebus.com.br/show.php?p=1\&id=65663. Acessado em 08 de setembro de 2006)

$\mathrm{Na}$ citação acima, ultrapassa critica ao "tom pejorativo" que se refere "ao telespectador médio brasileiro" e retoma a questão da seleção de informações que as industrias culturais fazem para atingir seus índices de audiência. Nesse sentido, mais uma vez estamos diante de duas questões fundamentais: em um primeiro momento a proibição do episódio "o feitiço de Lisa" e em outro a importância que o contado com "o telespectador médio brasileiro" poderia causar a imagem do governo de Fernando Henrique Cardoso que em 2002 estava desgastada devido a perda de estabilidade econômica vivida pelo Plano Real.

Com o desenvolvimento dos meios de comunicação, as antigas estórias que aguçavam a imaginação dos indivíduos, muitas vezes são substituídas por imagens reais que de forma 
alegórica, jornalística, histórica ou inventiva compõe o que Michel de Certeau (1994) chama de "a sociedade recitada". Com isso, inocentes desenhos que atingem o cotidiano dos indivíduos passando assim a compor um lugar importante para a análise historiográfica. Pois, as emoções, os incômodos, as angústias e as demais sensações dos homens, em inúmeros momentos são suscitadas após assistirem a cenas de telenovelas ou mesmo de desenhos animados. Ainda acerca da historiografia percebemos que temáticas referentes aos estudos sobre mídia carecem de ser mais bem exploradas, pois

na medida em que este instrumento que 'faz opinião' é manipulável por aqueles que o seguram, pode-se com razão perguntar sobre as capacidades que oferecem para mudar a 'crença' em 'desconfiança', em 'suspeita' e até mesmo em delação, como também sobre a possibilidade para os cidadãos de controlar politicamente aquilo que serve de fiabilidade circular e sem objeto a própria vida política. (CERTEAU, 1994: 291)

Comprovando a importância de tais discussões para a historiografia e a relação existente entre imperialismo e influência culturais intermediadas pela mídia televisiva, o pesquisador Marcus Vinícius de Freitas (2005), em artigo cujo titulo é “Greystoke, a lenda de Tarzan, o rei da selva", discute o evolucionismo e a crítica da ciência por meio de uma obra cinematográfica. Com tal intuito, Freitas discorre sobre a historicidade da produção do filme (título do artigo) dirigido por Hugh Hudson e produzido pela Warner Bros em 1983. Discute ainda sobre a criação do romance fundador Tarzan o rei dos macacos, de 1914. Situando estas questões temporais, ele afirma que "os Estados Unidos herdeiros culturais do colonialismo europeu, chegaram mais tarde, mais a tempo de serem os maiores beneficiados do rearranjo de poder que se seguiu a guerra e que perdurou pelo século XX” (FREITAS, 2005:132). Destacando três momentos históricos que vão da conjuntura do imperialismo do século, passando pelas guerras e atingindo o poderio americano no século XX, Marcus Vinícius enfatiza as seguintes discussões que fazem fundamentais para pensarmos nosso objeto de pesquisa. São elas: a perspectiva imperialista do século XIX referente à superioridade da raça branca que é problematizada no filme em análise; as distorções geradas pela ideologia do progresso e a atenção de que se deve haver ao se analisar a contextualidade da produção cinematográfica e os anseios populacionais que perpassam pelo público vivente do período. Nesta vertente, por mais que autor tenha seus objetivos específicos de produção, este, provavelmente é influenciado por um contexto histórico que é marcante na sua obra, mesmo mediante a subjetividade e individualidade do autor. Em meio a esta análise que contempla a produção e a recepção, o autor destaca:

Penso ser muito mais importante entendermos que o filme de Hugh Hudson responde a anseios da sociedade contemporânea, de encontrar respostas para 
as distorções geradas pela ideologia do progresso, e a ciência termina por ser um pouco o bode expiatório desse anseio coletivo. (FREITAS, 2005:144).

Esta perspectiva de estabelecer um diálogo entre as problemáticas vividas pela sociedade contemporânea, por meio da utilização de uma família marcada por traços tradicionais e modernos, também é uma das características marcantes da série Os Simpsons. Outro ponto que deve ser ressaltado, proposto pelo autor supracitado, diz respeito à perspectiva de civilização e selvageria que é presente em Tarzan e também no episódio d $O s$ Simpsons, "O feitiço de Lisa". Neste último, o Brasil é colocado como um país onde as pessoas convivem com macacos, cobras, bandidagem, prostituição e diversas sugestões de atraso civilizatório. Isto posto, mais uma vez estamos diante da discussão "do século XIX" do darwinismo social e da missão civilizadora que se fazem presentes em produções cinematográficas e seriados televisivos (como Os Simpsons) com certa frequência. Nesse sentido, destacamos que:

A desvalorização do nacional não provém unicamente das culturas audiovisuais e das transformações que a tecnologia telemática produz nas identidades, senão da erosão interna que a liberação das diferenças produz, especialmente das regionais e das próprias, às gerações. Vista a partir da cultura planetária, a nacional parece provinciana e carregada de laços paternalistas. (MARTIN-BARBERO, 2004, p. 43)

No século XIX as justificativas e propostas imperialistas sem dúvida eram também pautadas pela intermediação dos meios de comunicação. Porém, na contemporaneidade com o advento do rádio e da televisão no século XX, a potencialização de propagação dos interesses mercantis e políticos se dão com uma velocidade que ultrapassa as barreiras nacionais e geográficas, alterando o público destinatário dos programas e suas sensibilidades que são pautadas pelo recurso audiovisual. Nesse sentido, a ascensão americana pós $2^{\mathrm{a}}$. Guerra Mundial foi seguida de um desenvolvimento dos meios de comunicação que marcaram a guerra-fria. Sobre esta questão Marshall Mcluhan afirma que existiam no período da guerrafria "Quatro mundos". O primeiro capitalista, o segundo capitalista, o terceiro de países subdesenvolvidos e um quarto que se interpenetra os outros três e que sobrevive até os dias atuais que é o midiático. Esse mundo eletrônico da comunicação instantânea pode de acordo com o autor "chegar a África antes do primeiro e do segundo mundo". Ele considera ainda que assim como as ferramentas primitivas de comunicação a mídia eletrônica pode ser considerada como artefatos humanos que compõe a evolução do homem, pressuposto que nem mesmo Darwin poderia ter imaginado. Com tal premissa, ele faz uma discussão interessante que ressalta a tradição oral afirmando que as piadas podem ser causadoras de 
ressentimentos e muitas vezes passam a ser um tipo de comunicação desprezada pelos estudiosos. Atentos a nossa discussão, o pensamento de Mcluhan passa a ser fundamental, na medida em que o desenho dOs Simpsons e principalmente o episódio "O feitiço de Lisa" é caracterizado por zombar do Brasil e nossa discussão diz respeito exatamente ao ressentimento que tal episódio trouxe, principalmente para o presidente Fernando Henrique Cardoso. Assim destacamos:

Não pode haver piada sem ressentimento. $\mathrm{O}$ ritmo acelerado de nosso mundo produziu o chiste, a anedota abreviada. Os chistes são para as pessoas incapazes de prestar a atenção por muito tempo, que não tem paciência para esperar o fim da história. É preciso trabalhar depressa. Dizer uma única frase de impacto. (MCLHUAN, 2005, p. 331)

$\mathrm{Na}$ citação acima o autor destaca dois pontos importantes para a análise do desenho. No primeiro ele enfoca a "piada que traz ressentimento", pensamento que nos reporta não só as proibições supracitadas do episódio "O feitiço de Lisa" e as reações de empresas de turismo do Rio de Janeiro, como também a problemática concernente a seleção de público para tal episódio, na medida em que apenas pessoas com acesso a Internet e televisão por assinatura (FOX) puderam ter acesso ao episódio no Brasil. Ou seja, o público com acesso "ao ressentimento" ou não se restringiu e a "piada" acerca da realidade brasileira no governo de Fernando Henrique Cardoso não exposta a maioria dos brasileiros fato que sem dúvida evitou possíveis problemas no ano de 2002. Em outra vertente, Mclhuan chama a atenção para "a produção dos chistes" fato que caracteriza os programas televisivos e que nOs Simpsons ganha um grande acréscimo da "piada" e da animação fazendo com que a mensagem se torne ainda mais fácil para o telespectador. Evidente que aqueles que acompanham a série devem estar se indagando acerca da dificuldade das mensagens que por vezes não são tão simples como as dos demais desenhos. Porém, ressaltamos mais uma vez, que no episódio em que a família vem para o Brasil (o que estamos analisando) a ridicularização de nosso país se faz presente de forma extremamente explicita.

Umberto Eco em uma comunicação para o Congresso "Vision'67”, em Nova Iorque, em outubro de 1967, denominada "Guerrilha Semiológica" ressalta duas questões fundamentais para discussão entre a importância da televisão para a política e a pluralidade da recepção que pode demonstrar a importância do individuo na história, não como um mero telespectador mas como um sujeito ativo em seu tempo. Acerca da importância dos meios de comunicação na política ele destaca que:

Não muito tempo atrás, se quisessem tomar o poder político num país, era suficiente controlar o exército e a polícia. Hoje é somente nos países subdesenvolvidos que os generais fascistas, para dar um golpe de Estado, 
usam ainda tanques. Basta que um país tenha alcançado um alto índice de industrialização para que o panorama mude completamente: no dia seguinte a queda de Krushev os diretores do Pravda, do Izvestia e das cadeias radiotelevisivas foram substituídos; nenhum movimento do exército. Hoje um país pertence a quem controla os meios de comunicação. (ECO, 1984, p. 165)

Citando o então professor Mcluhan, Umberto Eco destaca ainda que a comunicação não era apenas um meio de produzir bens econômicos, mas sim o principal dos bens que poderia ser comparada a indústria pesada nos anos de Guerra-fria. A perspectiva do autor é extremamente relevante, pois já apontava para o poderio do uso dos meios de comunicação no século XX a serviço de interesses empresariais ou políticos. Todavia, o aspecto peculiar de " $\mathrm{O}$ feitiço de Lisa", conforme destacado anteriormente é que as imagens de Brasil projetadas no desenho ao mesmo tempo em que ridicularizam o país, também incomodam políticos e empresários, aspecto que sugere certo caráter de realidade, pois para além das opiniões e representações do país, a critica a pobreza, a sexualização da infância, a violência e ao carnaval nacional colocam em relevo problemas que, indiscutivelmente, fazem parte do cenário nacional. Sob esse ponto de vista é possível diagnosticarmos as motivações da censura ao episódio supracitado, mesmo acreditando que a liberdade de expressão é a principal máxima da política no século XXI, pois conforme atestou Hannah Arendt, em sua filosofia pluralista, o respeito as diferenças, o diálogo e a ação política de transformação são os principais pressupostos da condição humana. Nesse sentido, a censura não resolveu problemas estruturais, realmente, presentes em nosso país.

\section{Referências bibliográficas}

ARENDT, Hanna. A condição humana. Rio de Janeiro: Forense Universitária, 1969. BENJAMIN, Walter. "A obra de arte na época de sua reprodutibilidade técnica". In: Obras escolhidas I. São Paulo: Brasiliense, 1985.

Obra de arte na época de sua reprodutividade técnica. In: Teoria da cultura de massa. São Paulo: Paz e Terra, 2000.

BETTI, Paulo. Na marca do pênalti. In: NOVAIS, Adauto (Org.). Rede Imaginária: televisão e democracia. 2. ed. São Paulo: Cia das Letras, 1999.

BLOCH, Marc. Apologia da História ou ofício de historiador. Rio de Janeiro: Zahar, 2001.

CANTOR, Paul A. Os Simpsons: política atomística e a família nuclear. In: Os Simpsons e a Filosofia. São Paulo: Madras, 2004.

CERTEAU, Michel. A invenção do cotidiano: artes de fazer. Rio de Janeiro: Vozes, 1994. ECO, Umberto. Viagem na irrealidade cotidiana. Rio de Janeiro: Nova Fronteira, 1984. FREITAS, Marcos Vinicius de. Greystoke, a lenda de Tarzan, o rei das selvas: evolucionismo e critica da ciência. In: História da Ciência no Cinema. Belo Horizonte: Argvmentvm, 2005. GINZBURG, Carlo. Mitos, emblemas e sinais: morfologia e história. São Paulo: Companhia das Letras, 1989. 
IRWIN, Willian et al. Os Simpsons e a Filosofia. São Paulo: Madras, 2004. Os Super heróis e a Filosofia. São Paulo: Madras, 2005.

LE GOFF, Jacques. Documento/Monumento. In: Enciclopédia Einaudi: Memória e História. Lisboa: Antroposomem, 1989.

LE GOFF, Jacques. Prefácio. In: Apologia da História ou ofício de historiador. Rio de Janeiro: Zahar, 2001.

MCLUHAN, Marshall. Mcluhan por Mcluhan: conferencias e entrevistas. Rio de Janeiro: Ediouro, 2005.

Visão, som e fúria. In: Teoria da cultura de massa. São Paulo: Paz e Terra, 2000.

MARTIN-BARBERO, Jesus. A comunicação no projeto de uma nova cultura política. In: Comunicação na América Latina: desenvolvimento e crise. José Marques de Melo (org). Campinas: Papirus, 1989. p. 83-98.

UFRJ, 2001.

Dos meios as mediações: comunicação, cultura e hegemonia. 2. ed. Rio de Janeiro:

. Os exercícios do ver: hegemonia audiovisual e ficção televisiva. 2. ed. São Paulo: Senac São Paulo, 2004.

MIGUEL, Luis Felipe. Política e mídia no Brasil: episódios de uma história recente. Brasília: Plano Editora, 2002. 